\title{
Neuropathology of the oesophagus in diabetes mellitus
}

\author{
BARBARA SMITH \\ From the Department of Pathology, St Bartholomew's Hospital, London
}

SYNOPSIS Abnormalities of the innervation of the oesophagus have been shown in 18 out of 20 unselected diabetics without clinical dysphagia or neuropathy. The changes appear to be in the axons of the extrinsic and intrinsic parasympathetic fibres. It is probable that, as in the peripheral nerves, the major changes are in the Schwann cells, although here the affected fibres are unmyelinated.

Autonomic neuropathy is known to occur in diabetes, but the changes in the innervation of the alimentary canal have not been studied. Frank dysphagia is rare, but Ellenberg and Cohen (1968) describe two patients. Radiological evidence of impaired oesophageal peristalsis was described in 24 out of 25 symptomfree diabetics by Vela and Balert (1970), and 12 out of 14 similar patients by Mandelstam and Lieber (1967). Similarly, impaired gastric emptying has been demonstrated in some patients by Swarts and Stine (1948), Malins and French (1957), and Zitomer et al. (1968). These findings would suggest that there is an abnormality of the innervation of the alimentary tract, although clinical symptoms are rare. Coërs and Hildebrand (1965) have shown that abnormalities of the terminal innervation in skeletal muscle can be seen commonly in diabetes without neuropathic symptoms.

In this work, unselected diabetics without clinical neuropathy were studied.

\section{METHODS}

Twenty unselected patients dying with diabetes mellitus were examined, 14 treated with insulin and six with hypoglycaemic agents. The duration of the disease was one month to 45 years. One patient had had a total pancreatectomy three years previously and one had steroid-induced disease of four years' standing. No patient complained of symptoms relating to neuropathy but some had neurological signs such as impaired vibration sense or reduced ankle jerks.

The oesophagus was opened and fixed flat, and examined in paraffin section and by silver impregnation of the myenteric plexus (Smith, 1967). Three

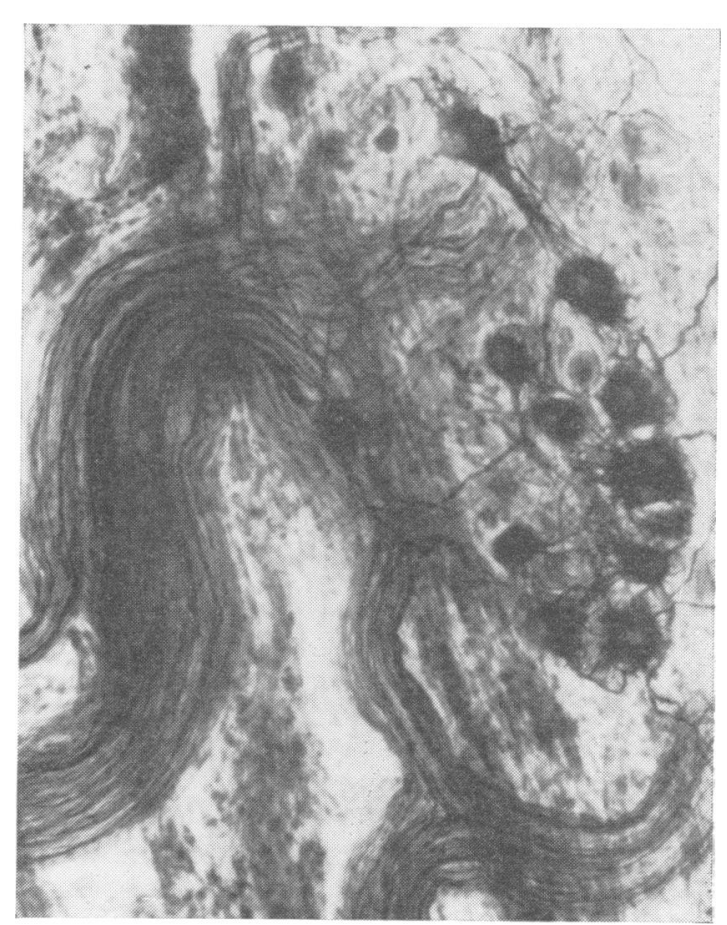

FIG. 1. A normal oesophageal myenteric ganglion. Schofield, $\times 150$. 


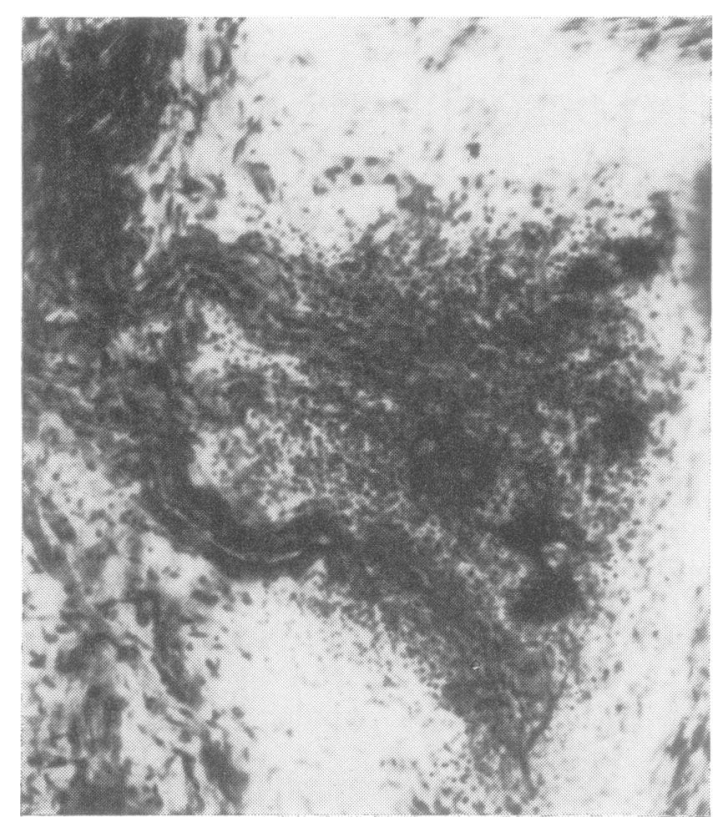

FIG. 2. An oesophageal myenteric ganglion from a patient who had been diabetic for 45 years and treated with insulin. Neurones remain, but the ganglion is infiltrated with lymphocytes. Schofield, $\times 150$.

blocks were taken in each case. In eight cases the vagus was taken both behind the carotid artery and from the lower oesophageal wall and osmiumstained blocks teased under the dissecting microscope.

\section{RESULTS}

Eighteen out of 20 patients showed definite pathological abnormality of the innervation of the oesophagus. There was no difference between patients treated with insulin and those treated with hypoglycaemic agents. Duration played little part; the patient diagnosed as diabetic for only a month had mild changes but some patients with disease lasting only three or four years were as bad as the patient who had had it for 45. The two patients showing no abnormality had both been treated with insulin, one for 15 years and the other for 21 years.

Examination of the oesophagus in the 18 cases with pathology showed that the neurones of the myenteric plexus were largely normal. A small

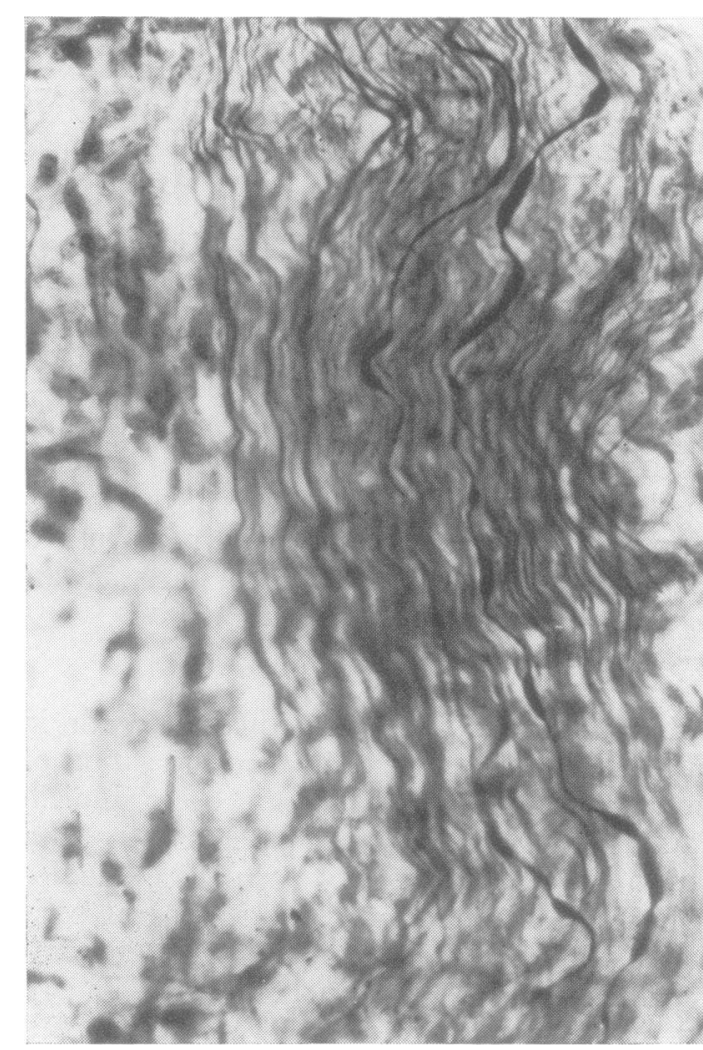

FIG. 3. A nerve trunk from the oesophageal myenteri $\overrightarrow{0}$ plexus of a patient, diabetic for five years and treated with insulin. The parasympathetic fibres show calibre irregularities. Schofield, $\times 350$.

number had swollen irregular processes and in one case there was vacuolation of nerve cells. There was, however, a very marked increase in the number of non-neuronal cells in the ganglia, mainly lymphocytes. This was obvious on the thicker silver preparations, but in three cases it could be seen easily on the paraffin sections (Figs 1 and 2). Another finding was swelling, irregularity of calibre and minor disruption of parasympathetic fibres both within the myenteric plexus and in the extrinsic trunks (Figs 3 and 4). In the normal subjects, the parasympathetic fibres are thick, straight, and of an even calibre, and can readily be distinguished from the fine closely packed sympathetic axons. In other contexts similar changes have been seen in 


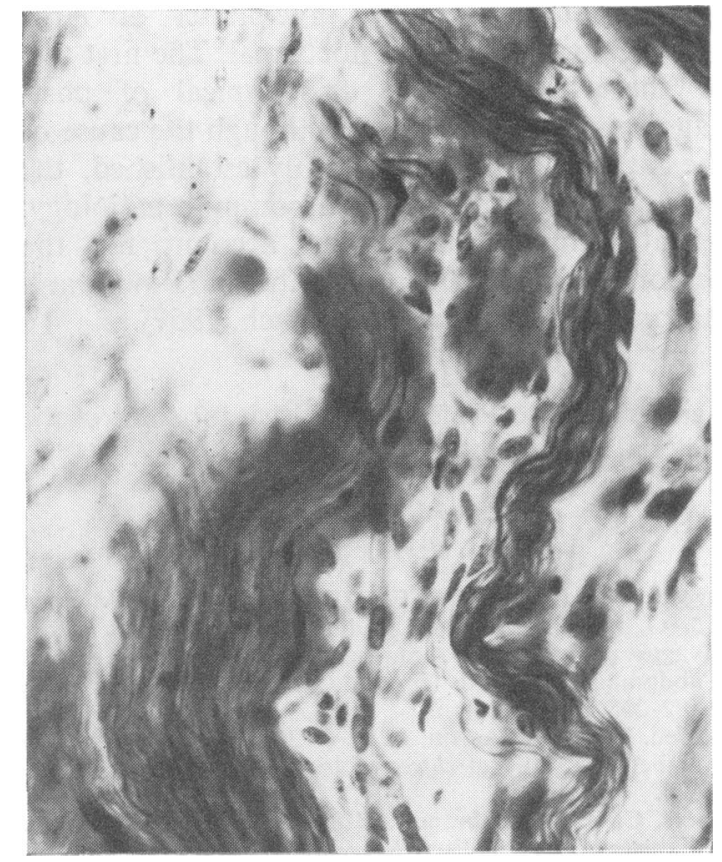

FIG. 4. A nerve trunk from the oesophageal myenteric plexus of the same patient as illustrated in Fig. 2. One parasympathetic fibre is beaded. Schofield, $\times 350$.

axons in the same specimens which have shown segmental demyelination, so it may represent Schwann cell disease in the unmyelinated fibre. A more severe change, seen in five cases only, were balloon-like swellings along the length of the axon (Fig. 5) and in two cases there were retraction balls. These changes can also be seen after vagotomy and in vagal damage by malignant disease and correspond to more severe fibre disruption. The sympathetic fibres appeared normal in all cases, but the fibres are a good deal finer and pathology might be more difficult to see.

Examination of the vagus by teasing osmiumstained preparations showed only a small number of segmentally demyelinated fibres and a rather larger number showing Wallerian change (Fig. 6). In the vagus taken in the neck the number of abnormal fibres was very small but they were slightly easier to find in portions of vagus taken at diaphragmatic level.

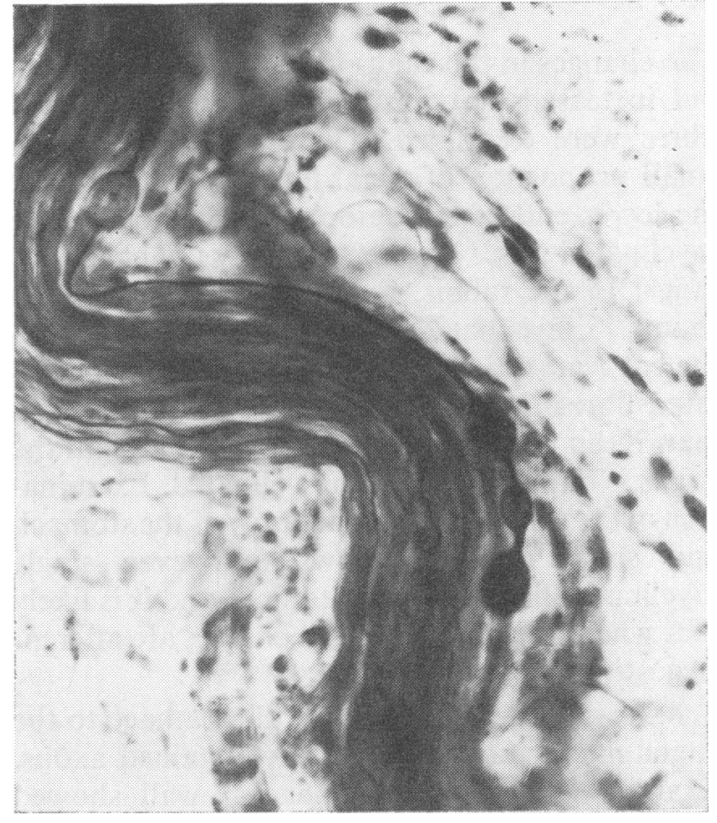

FIG. 5. A nerve trunk from the oesophageal myenteric plexus of a patient, diabetic for seven years treated with insulin. There are axonal swellings on a parasympathetic fibre. Schofield, $\times 350$.

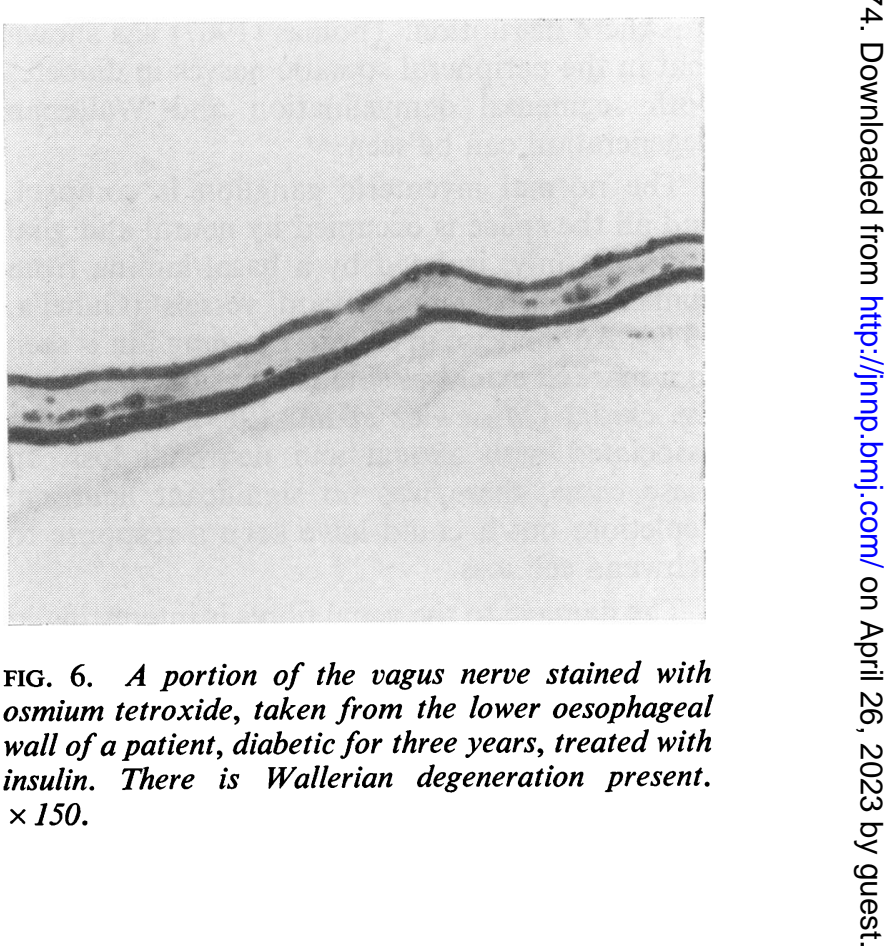




\section{DISCUSSION}

The changes in the vagus were not very plentiful, but in teased preparations only the myelinated fibres were examined. These represent only a small proportion of vagal fibres, particularly at the lower end of the oesophagus as most of the myelinated fibres appear to supply the heart and lungs. In the rabbit, Evans and Murray (1954) found 75 myelinated fibres out of 26,000 and in the cat Agostini et al. (1957) showed 400 medullated fibres out of 31,000 at the diaphragm. In man Keen (1966) said that at the diaphragm the vagus is almost entirely unmyelinated. Examination of the parasympathetic supply of the stomach and small intestine shows that even single myelinated fibres are hard to find, and it is likely that what myelinated fibres there are, are afferent (Agostini et al., 1957).

Assessment of the extent of the damage to the vagus must rest mainly on silver-stained axons. Examination of the oesophageal wall showed that abnormalities were present on the parasympathetic axons in both extrinsic and intrinsic trunks, whereas the neurones were normal. The latter would agree with the finding that there is no cholinergic hypersensitivity (Ellenberg and Cohen, 1968). The changes seen in the axons were mainly those thought to be associated with Schwann cell disease and only in severe cases was there disruption. Thomas (1967) has shown that in the peripheral somatic nerves in diabetes both segmental demyelination and Wallerian degeneration can be seen.

The normal myenteric ganglion is compact, and all the space is occupied by neural and glial elements only, isolated by a basal lamina from connective tissue and blood vessels (Gabella, 1972). An increase in cells in the ganglion is seen to a marked extent in some cases of achalasia of the cardia (Misiewicz et al., 1969), where it is associated with axonal and neuronal loss. In these cases, there was no significant neuronal depletion, but it could have been a response to Schwann cell loss.

The damage to the vagal fibres is interesting in the context of diabetic diarrhoea. This is an uncommon complication but has a characteristic symptomatology, being precipitate, of large volume, and sometimes nocturnal. The first two of these features are also typical of postvagotomy diarrhoea, and, although the cause of the latter has not been firmly established, the two conditions may have a common aetiology. Vagal damage might also account for the achlorhydria seen in some diabetics (Bowen and Aaron, 1926; Malins and French, 1957).

I am grateful to Professor H. Urich for some of the material used in this study.

\section{REFERENCES}

Agostini, E., Chinnock, J. E., Daly, M. de B., and Murray, $\vec{\omega}$ J. G. (1957). Functional and histological studies of the vagus nerve and its branches to the heart, lungs and abdominal viscera in the cat. Journal of Physiology, 135, 182-205.

Bowen, B. D., and Aaron, A. H. (1926). Gastric secretion in diabetes mellitus. Archives of Internal Medicine, 37, 674 $\overrightarrow{0}$ 684.

Coërs, C., and Hildebrand, J. (1965). Latent neuropathy in $\vec{\sim}$ diabetes and alcoholism. Neurology (Minneap.), 15, 19-38्ठ

Ellenberg, M., and Cohen, B. (1968). Diabetic esophageg neuropathy. (Abstract.) Diabetes, 17, 322.

Evans, D. H. L., and Murray, J. G. (1954). Histological an functional studies on the fibre composition of the vagus nerve of the rabbit. Journal of Anatomy, 88, 320-337.

Gabella, G. (1972). Fine structure of the myenteric plexus the guinea-pig ileum. Journal of Anatomy, 111, 69-97.

Keen, J. A. (1966). A note on the fibre composition of thention vagus nerve in man. South African Medical Journal, 40, I 981-984.

Malins, J. M., and French, J. M. (1957). Diabetic diarrhoea. Quarterly Journal of Medicine, 26, 467-480.

Mandelstam, P., and Lieber, A. (1967). Esophageal dysfunction in diabetic neuropathy-gastroenteropathy. Journal of the American Medical Association, 201, 582-586.

Misiewicz, J. J., Waller, S. L., Anthony, P. P., and Gummer, 르 J. W. P. (1969). Achalasia of the cardia: pharmacology and $\overrightarrow{\vec{T}}$ histopathology of isolated cardiac sphincteric muscle from $O$ patients with and without achalasia. Quarterly Journal of Medicine, 38, 17-30.

Smith, B. (1967). Myenteric plexus in Hirschsprung's disease. Gut, 8, 308-312.

Swarts, J. M., and Stine, L. A. (1948). Visceral neuropathy complicating diabetes mellitus. American Journal of Medicine, 5, 601-615.

Thomas, P. K. (1967). Diabetic neuropathy: morphological aspects. Proceedings of the Royal Society of Medicine, 60, 145.

Vela, A. R., and Balart, L. A. (1970). Esophageal motor manifestations in diabetes mellitus. American Journal of Surgery, 119, 21-26.

Zitomer, B. R., Gramm, H. F., and Kozak, G. P. (1968). $\frac{D}{0}$ Gastric neuropathy in diabetes mellitus: clinical and radio-․ㅡ․ logic observations. Metabolism, 17, 199-211. 